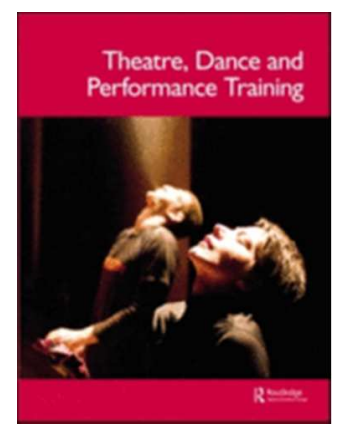

\title{
Immersive Awareness
}

\begin{tabular}{|r|l|}
\hline Journal: & Theatre, Dance and Performance Training \\
\hline Manuscript ID & RTDP-2017-0023.R1 \\
\hline Manuscript Type: & Special Issue Article \\
\hline Date Submitted by the Author: & n/a \\
\hline Complete List of Authors: & $\begin{array}{l}\text { Middleton, Deborah; University of Huddersfield, Music and Drama } \\
\text { Núñez, Nicolás; UNAM Faculty of Arts }\end{array}$ \\
\hline Keywords: & Immersion, Awareness, Meditation, Theatre of Sources, Perception \\
\hline \multicolumn{2}{|l}{} \\
\hline
\end{tabular}

SCHOLARONE ${ }^{\text {m }}$

Manuscripts 


\section{Immersive Awareness}

Deborah Middleton (University of Huddersfield)

and

Nicolás Núñez (UNAM, Mexico)

Dr. Deborah Middleton (Corresponding Author)

Drama, Theatre and Performance

University of Huddersfield

Queensgate

Huddersfield, HD1 3DH

Tel: 07876527899

Email: d.k.middleton@hud.ac.uk

\author{
Nicolás Núñez \\ Taller de Investigación Teatral \\ UNAM, Mexico. \\ Email: nicolas_ehehcatl@hotmail.com
}




\begin{abstract}
:
This paper explores an approach to training for immersive theatre performance which addresses the need for an expanded and multi-focal awareness. Drawing on The Movements from Grotowski's Theatre of Sources period, Núñez's training process for El Ensueño de los Árboles (2017) is discussed in terms of meditation-in-movement and deconditioning of perception. This training is considered as a training in the capacity for immersion.
\end{abstract}

Keywords: Immersion, meditation, perception, awareness, Theatre of Sources. 
Immersive Theatre: Participation and Performance

Contemplative and immersive theatre experiences, such as El Ensueño, depend, for their effectiveness, upon the ability of the performers to facilitate a deep and uninhibited engagement on the part of the audience. The guided meditation which is at the heart of El Ensueño invites participants into a state of active contemplation. This constitutes a significant shift away from daily consciousness and habitual social behaviours. In this respect, the intention of El Ensueño might be said to exemplify one defining feature of Immersive Theatre, as identified by Josephine Machon:

\footnotetext{
1 The performance was written and devised, and the training process described here was carried out, during a three-week residency in the autonomous, indigenous territory of Guna Yala, Panama. Núñez led the training and devising process; Middleton wrote the performance text. The creative team in Panama included Domingo Adame and Caroline Clay. The team were joined in Mexico City by Helena Guardia.
} 


\footnotetext{
${ }^{2}$ Núnez has created several immersive forest performances. See, for example, Cura de Espantos (1998) described in Middleton 2001, pp. 56 - 60.

${ }^{3}$ This paper is co-authored but where an individual voice is inserted, the text is given it italics and the speaker is identified by initials in parentheses.
}

\begin{abstract}
Immersion as absorption. The theatre event is able to engage the participant fully in terms of concentration, imagination, action and interest; a total engagement in an activity that engrosses (and may equally entertain) the participant within its very form. (Machon 2009, p.
\end{abstract} 62)

For immersive theatre to fulfil this potential, Machon's research suggests that a number of conditions must be met: the participant must understand the 'contract' that determines their engagement (Machon 2009, p. 99); a 'safe space' must be established (Machon 2009, p. 41), and 'mutual trust' generated (Machon 2009, p. 84).

In addition to their artistic roles, performers in work such as El Ensueño ${ }^{2}$ are also what we call 'monitors'; their role is to guide audiences through the participatory actions, and establish (both silently and explicitly) what Machon calls the contract for engagement. They are charged with safeguarding the audience-participants - both physically and through creating an emotionally safe space in which they can move and interact freely and spontaneously. The monitors must be attentive to each individual member of the audience, anticipating their needs and interacting with them accordingly. This requires a level of careful vigilance. We must be two steps ahead, in every direction $(\mathrm{NN})^{3}$.

Comment [D1]: This and the followng paragraphs have been re-organised to clarify the steps of the discussion. 
Beyond this fundamental groundwork, the participant must be brought into an 'all-encompassing' experience (Machon 2009, p. 40), in which they can 'experience more fully' (Machon 2009, 26), 'let down their boundaries' (Machon 2009, p. 42), be 'in the moment' and 'receptive' (Machon 2009, p. $84)$ to the imaginative and sensory stimuli available to them.

In El Ensueño, our purpose was to address these challenges through the presence of the performer. ${ }^{4}$ Bringing the participant into a full and deep experience is, for us, about leading through example. The performer-monitors model how the audience-participants might listen, look, move, and interact with, and in, the natural environment (Figure 1). At its simplest, this entails maintaining silence; cessation of normal, non-verbal social contact; paying attention to the environment; moving softly and unobtrusively; and making contact with others in extra-daily ways.

Machon also notes that immersive theatre carries the possibility of 'emotional or existential transformation' (Machon 2009, p. 63) ) $^{5}$ but that for this to occur a significant shift must be facilitated - from a daily mode of being to a deepened or heightened mode (Machon 2009, p. 42). In our work, the performer-monitors demonstrate, by way of an invitation to the audienceparticipants, a heightened mode of experiencing.

\section{Drawing on the terminology of meditation ${ }^{6}$, we might describe this} mode as a form of 'mindfulness'. Varela, Thompson and Rosch write,

\footnotetext{
4 They are also addressed structurally and textually.

5 See Machon 2009, pp. 60 to 62 for her notion of 'transportation'.

6 Tibetan Buddhist meditation is a key influence on both authors. See Núñez 1996, pp. 1 - 17, and Middleton, D. \& M. Adkins., 2016. 'Borderlands: An Exploration of Contemplation in Creative Practice' in Liminalities: A Journal of Performance Studies. Vol. 12, No. 2, 2016.
} 
To get a sense of what mindfulness meditation is, one must first realize the extent to which people are normally not mindful. [...] In fact, body and mind are not coordinated. In the Buddhist sense, we are not present. (Varela, Thompson and Rosch 1993, p. 24)

Over time, meditation practices counter the habitual, daily 'dissociation of mind and body, of awareness from experience' (Varela, Thompson and Rosch 1993 , p. 25) thus increasing the meditator's capacity to enter into states of heightened - mindful - awareness and presence. In El Ensueño, the performer-monitors seek to model mindfulness in action.

In crude terms, then, this means that the performer-monitors have two major points of focus and realms of responsibility: the external world of the environment and audience, and the internal world of their own embodied, mindful process. The ideal performer-monitor in this work would be in a state simultaneously of deep inner meditation and full outer attention; (although perhaps this is an optimal state for acting in any theatrical context?). Central to the actor's ability to perform these functions simultaneously is the capacity for an expanded and multi-focal awareness.

Here, we explore an approach to the training of performer-monitors which entails the cultivation of an extended awareness in the actor. Further, we propose that such an approach actually represents a training in the capacity for immersion. It is this embodied capacity in the performer-monitors which enables the audience-participants to fully immerse themselves in the performance and to access non-daily depths of experience. 


\section{From Theatre of Sources to El Ensueño} In establishing the historical trajectories that led to the emergence of immersive theatres, Machon notes the role of Grotowski's work in Paratheatre, Theatre of Sources, and Art as Vehicle (2009, p. 38). In El Ensueño, that lineage is very consciously mined. Whilst Grotowski himself did not create immersive theatre, the experiences in 'active culture' (Kolankiewicz, 1979) that he developed in the post-production years were focused precisely on techniques for intense immersion in direct experience. Paratheatre and Theatre of Sources sought to offer to participants what Grotowski described as 'experiences of direct perception, with the whole self, literally' (Kolankiewicz 1979, p. 30). Kolankiewicz writes that such experiences,

...would then enable man to find himself in the situation where existence itself would look at him; where his sense would not be walled up; where he would be immersed in existence. Where - as Grotowski puts it - he would enter the world as a bird enters the air. (Kolankiewicz 1979, p.13)

Nicolás Núñez, who led the training process for El Ensueño, and Helena Guardia who was part of the performance team in Mexico City, both worked with Grotowski in Theatre of Sources during the period 1980 to $1981^{7}$. Whilst Núñez and Guardia's work in the Taller de Investigación Teatral bears many hallmarks of Grotowski's influence, the training for El Ensueño, as we shall

\footnotetext{
${ }^{7}$ Other periods of work with Grotowski included an Objective Drama project in Mexico, in 1985. See Núñez 1996, 51 - 64.
} 
see, directly recalled, in both technique and intention, The Movements from Theatre of Sources.

Although the work in Theatre of Sources was not framed as a training for actors, it was, nevertheless, an activity aimed at actors ${ }^{8}$, and focused on cultivation techniques. For Núñez and Guardia, the work was tacitly a training for both the leaders and the participants. Guardia recalls,

We re-learned to see, to listen, to smell and to touch, to open our mind beyond the dominance of the limiting left brain. We trained the attention and the body; our mental, emotional and physical resilience, in order to deconstruct our conditioned selves, changing our perspectives and accessing, if only for a glimpse, the reality of interconnectedness, a new way of being. (Guardia 2017a)

Additionally, Núñez and Guardia learned, in Theatre of Sources, how to lead others through short, intensive experiences of the practices they themselves were engaged in extensively over many months. In training for our roles as performer-monitors in El Ensueño, we drew directly on Núñez and Guardia's experiences in Theatre of Sources. As we describe below, The Movements provided us with a vehicle through which to cultivate our capacity for immersion, and to develop the expanded awareness required to model that capacity whilst guiding others.

\section{The Training}

\footnotetext{
8 Unlike some versions of the earlier paratheatre explorations, Theatre of Sources was not for the general public; visiting participants were required to have a theatre background (NN).
} 
The training undertaken in Guna Yala can be divided into two phases: 1) introductory work, designed to sensibilise the performers, and to facilitate initial contact with, and attunement to, the environment; 2) daily training in a precisely repeated structure, designed to cultivate awareness, and to facilitate deep immersion in the environment. Here, we shall focus on three examples of practice: Beach Action and Sea Action from the sensibilization work, and our central training form, River Action, which utilised a section from The Movements.

\section{Sea Action: Sensibilisation}

Eyes closed, the performer walks slowly into the sea, feeling the movement of the waves and currents. A monitor walks with her, without disturbing her experience. With eyes closed, her exteroceptive sense and her sense of hearing become more acute. Proprioception is challenged as she steadies herself in the unbalancing push and shove of the waves.

Feel how the waves arrive to the beach, notice the never-ending movement... we are working with mind and body... feel the massage of the waves, feel the flow of the waves... (NN)

The performer notices what arises for her in this sensory bath. With eyes closed, the complexity of the wave forms, the trajectories of the currents, and the interplay of warm and cool streams are more discernible. We notice our hesitancy or joy, our resistance or our excitement. We notice whether we feel 
...feel the flow of the waves... we are learning to be with the flow of the universe... Be here with consciousness, and go with the flow... (NN)

Núñez's theatre practice has long explored psychophysical training at the interface of the human and cosmic dimensions. In his introduction to Anthropocosmic Theatre: Rite in the dynamics of theatre, he notes that 'When we study our body; we are also studying part of the cosmos' (Núñez 1996, p. xviii). This vast ecological perspective, when deployed in the training sphere, is not intended to instigate cognitive reflections, but rather to guide awareness outward, through and beyond the sensory surface of the body. The dissolution of muscular armouring that accompanies relaxation into somatic sensation is

\footnotetext{
${ }^{9}$ For a discussion of the neurological basis of embodied awareness, see Alan Fogel (2009) Body Sense: The Science and Practice of Embodied Self-Awareness. New York, London: W. W. Norton.
} 
in service of a more intensified experience of the reality in which we find ourselves. What Will Johnson writes about the effects of meditation posture might hold equally true for a somatic 'meditation' such as Sea Action -

\begin{abstract}
The relaxation of tension also enables us to hear and see with greater clarity, and the internal monologue of the mind naturally begins to subside. As we learn to experience the components of reality (our sensations, sights, sounds, tastes, smells, and thoughts) with greater ease and precision, we naturally begin penetrating to an awareness of even deeper levels of that reality. (Johnson 1996, p. 41-42)
\end{abstract}

At a certain moment in Sea Action, after some time entering and experiencing the sea's motion, the performer is instructed to open her eyes. The world appears. Keeping her gaze open, eyes level and directed straight ahead, she turns slowly in a 360 degree circle, three times. The whole panoramic scope is received: the sea horizon, the sea, the jungle where it edges the sea, the village, the river, the beach beyond the river, the big expanse of the sea, the sea horizon... (DM).

If moving from closed eyes to open eyes heightens one's sense of visual input, the panoramic gaze exercise prolongs and deepens that impact; suspending the performer in the intensified act of seeing. This work with panoramic gaze was continued in Beach Action.

\title{
Beach Action: Working with the Gaze
}


${ }^{10}$ For a discussion of Núñez's contemplative running, see Middleton 2001, pp. 51 53.

${ }^{11}$ Middleton studied Mudra Space Awareness with Lee Worley during a Visiting Scholar sabbatical at Naropa University (August to December, 2010).

Single-file - 'in serpent' - the performers make a long contemplative run ${ }^{10}$ on the beach, with gaze open. We stop, and turn slowly through a series of 360 degree turns, again maintaining the disciplined use of vision described above. In her journal, performer Caroline Clay noted:

I can see ocean, forest, sand and sky all at once and a few times I feel like this is a lot to be seeing or perceiving in one moment... the sensation is intense.... I'm playing with the boundaries of my vision and making an attempt to see in a way that is not everyday seeing... almost as soon as we began to turn, I felt quite overwhelmed (physically and emotionally). The enormity of the world (and beyond) and my place in it... Since the turning, I feel more like I 'belong' in this landscape. (Clay 2017a)

The use of an open gaze with diffuse attention and extended peripheral vision is common in Núñez's training dynamics, but this practice was also influenced by Middleton's training, led by Lee Worley, in Mudra Space Awareness $(\mathrm{MSA})^{11}$. MSA was developed by the Buddhist master, Chogyam Trungpa Rinpoche as a practice for theatre artists. In Trungpa's exercise, The Presence of Being, participants stand silently in a circle, then, one at a time, weave through the circle, focusing 'on maintaining a broad and constant awareness... attention should be paid to the eye gaze, letting it rest openly on 
a low horizon and taking care on turnings that the eyes neither dart ahead nor lag behind' (Worley 2010, p. 69).

It is common for participants in these exercises to find that the habitual movement of the eyes is quite disconnected from the movement of the body, and that there is a strong tendency for the eyes to move ahead, governed perhaps by impulsive - Trungpa might say 'neurotic' (Trungpa 1994, p. 75) mental movements. Preventing the eyes from darting to particular points in the view generates a much more mindful and consciously receptive mode of perception.

In meditation practice, it is said that the eyes are the first windows to the mind; hence, stilling the movement of the eyes is considered to be a helpful technique for settling the mind. In meditation, this is done through closing or half-closing the eyes; in yoga asanas, a dristi point enables the gaze to be stabilized. Training the gaze can, however, have additional challenges and additional functions.

Grotowski tells us that when,

...daily, habitual techniques of the body... are suspended... what first appears is deconditioning of perception. Habitually, an incredible quantity of stimuli are flowing into us, from outside something is "speaking" to us all the time, but we are programmed in such a way that our attention records exclusively those stimuli that are in agreement with our learned image of the world... (1997a, p. 259) 


\section{RIVER ACTION: Expanded Awareness ${ }^{12}$}

In serpent, the performers walk silently on a rough path from the village into the jungle. The walk takes approximately 15 minutes and covers terrain which is often muddy and slippery. We cross a stream, forded by stones which are also wet and slippery. Maintaining a consistent distance to the person in front, or maintaining a steady pace if one is leading, requires a certain vigilance under these conditions; an effort to meet the mud and the river and the rocks

\footnotetext{
${ }^{12}$ Video of the sequence described here can be found at: https://www.youtube.com/watch?v=oeEYL5xZmQg. The core training sequence begins at 1.53. With Nicolás Núnez, Deborah Middleton, Caroline Clay, Domingo Adame. Video: Sofie Iversen.
} 
and the over-hanging tree branches smoothly, steadily. Dropping behind or making sudden movements is discouraged. Gaze is, as much as possible, levelled directly ahead and open.

It's a contemplative walking, it's not an ordinary walking... the main intention... is to make this contemplative walking, warming up our situation, in order that when we reach [the river] we prepare ourselves to go deep; to open the perception with more intention - physical and mental - to take the deepest layers of reality that we can... (NN)

As this is a 'contemplative walk' we treat it as a meditation, stepping mindfully so as not to disturb the environment nor impose ourselves upon it, and watching our minds. We are in a remote and beautiful jungle, and even here the tendency for the mind to wander and get lost in thought is ever-present. We are quite committed to dispersions, to distractions... (NN).

Arriving at our chosen point on the river, we make our way to river rocks with flattish surfaces that are not too slippery, or stand on the shingly river bed. The river has come down from the mountain, and it is cold; at first refreshing, and then sometimes numbing (Figure 2).

We stand, aware of alignment, gaze open; slowly, the arms are raised up, level with the body laterally, elbows bent, hands pointing up, palms facing forward (Figure 3). The hands frame the vista directly in front of the eyes. Bending at knees and hips, the practitioner angles forward through the frame of the hands, as though looking through a window, or portal; as though penetrating into the view framed by the hands (Figure 4). The legs and trunk 
You have to watch your mind, it's like a meditation in movement, you have to be alert. (NN)

After several minutes, using peripheral vision to enable us to move together, we slowly return to the starting position. After a small pause, the hands are again raised. This time, the upper body and head and the arms in their framing position are lifted and dropped back in a slight backbend so that the gaze is now directed up towards the sky (Figure 5). As before, the position is maintained for some moments, during which time the practitioner again anchors awareness in the global experience of body, breath, mind movement, and environment. Mind wandering and discursive thought are avoided. After some minutes, the practitioner returns smoothly to the starting position, without losing attention or disrupting the openness of the gaze.

This sequence is repeated three times. Then, the group, together, make a quarter turn to the left. The complete action involves performing the sequence in each of the four directions. At the end of the final sequence, the 
When I say to you to catch the perfume of the jungle, it is for you to become the jungle. In that river, I open my inner situation to become the jungle. The jungle comes to me and maybe something appears. I become with the jungle, and it is in me. If I am blessed, I've been touched. And if I am willing.... [later], I put myself here and something of the jungle might come again. (NN)

Our stated reason was catching and retaining the perfume related to our performance roles. If, as good Actors, we could internally recover that 'perfume' when we performed El Ensueño in other places, then - perhaps something of the jungle would be made present for our audiences elsewhere. Our outer performance would be imbued with a quality arising directly from the vivid inner score of sensory memory, with all of its personal and cultural 
associations and resonances. Whether or not we were successful in evoking the perfume of Guna Yala in our subsequent performances, the intention to catch and hold something of our jungle experience served an important training function. The instruction to capture the 'perfume' carried us beyond a passive construal of the receptive nature of the disciplined bodymind, and instigated an active and relational state of presence.

\section{Sources}

The central movement sequence in River Action was recalled from The Movements, an action developed in Theatre of Sources, some forty years earlier. The structure of Theatre of Sources involved specially selected practitioners developing particular 'source techniques' over many months, then sharing them with public groups in specially organised events. From late 1980 until the end of 1981, Núñez and his long-term collaborator, Helena Guardia, were part of the Theatre of Sources team in Poland. Whilst Núñez developed the form of contemplative running that would later be a keystone of his anthropocosmic theatre dynamics, Helena Guardia worked alongside Denis Le Turcq on The Movements.

The Movements were a flowing sequence of yoga asanas, performed slowly, with open visual awareness in a multi-directional pattern. Later, in Objective Drama, this sequence was refined into what Lisa Wolford has described as 'an extremely precise exercise', (1997, p. 287) known as The Motions ${ }^{13}$. During Le Turcq and Guardia's early phase of exploration, however, the Movements were explored with more freedom, seeking an inner

\footnotetext{
13 Thomas Richards notes that the Motions was developed and refined between
} 1979 and 1987, at which point it was finalized (Richards 1995, p. 52). 
sense of energetic alignment, rather than referring to detailed outer-form instructions. Guardia notes that, in The Movements, 'The emphasis was on focusing, even if the pose was not perfect' (2017). River Action was also introduced and explored in this spirit.

In Poland, The Movements and the other Theatre of Sources actions were practised in the forest, and were both meditative and outwardly orientated. The 'sources' to which Grotowski's Theatre of Sources referred were traditional psychophysical techniques such as those found in Yoga, Sufism, Buddhism and other 'spiritual' traditions. In particular, he explored techniques that were 'active', as opposed to, for example, sitting meditation (Kumiega 1987, 232) and 'ecological' -

Ecological in the human way means that they are linked to the forces of life, to what we can call the living world... (Grotowski 1997a, p. 259)

Grotowski's intention in mining these cultural sources was to connect with 'sources' in another sense; 'to bring us back to the sources of life, to direct, so we say, primeval perception, to organic primary experience of life.' (Grotowski in Schechner 1997, p. 214).

Technically, The Movements were an adaptation of Hatha Yoga ${ }^{14}$, with the addition of elements designed to further emphasise the active and ecological functions; for example, the sequencing of the 'asanas' in an

\footnotetext{
${ }^{14}$ For a discussion of Grotowski's work with yoga, see Kapsali, M., 2010. "I don't attack it but it's not for actors': the use of yoga by Jerzy Grotowski'. Theatre, Dance and Performance Training. Vol. 1(2), 2010, 185 - 198.
} 
River Action involved this 'diffuse' form of panoramic gaze, projected outward in a particularly penetrating way through the frame of the hands. Keeping ones eyes trained to the edges of peripheral vision, sight is extended laterally whilst also reaching into the depths of the view framed by the window of the hands.

I Wayan Lendra's record of The Motions from 1983 to 1986 is significantly different from Guardia's memory of the Movements; by this time, it seems that the framing hand position was no longer included. The panoramic gaze, however, continued to be a key element. Lendra writes,

To really see with panoramic vision is difficult. When you are able to see in a panoramic view, your perception cannot be as focused as when you see only one thing. This is difficult because in daily life we constantly focus... But the requirement of the Motions is that you must not react to any one thing but must fully perceive all that there is to see 
and hear. To see and hear and not to react... is a contradiction. This contradiction creates "life" and self-awareness. (Lendra 1997, p. 127)

Thomas Richards similarly notes that in his work with The Motions, the instruction was to 'see as if through a big open window' (Richards 1995, 54). In The Motions, and in The Movements before it, we have a psychophysical structure designed to alter consciousness, in part through altering perception. Attention to the energetic alignment of the 'asanas' ${ }^{15}$, coupled with the disciplining and dilation of perception, creates a form in which the mind is trained into new, non-daily patterns. The non-reactive mode which Lendra notes is characteristic of meditation training, and has the effect of inducing a more receptive mode of engagement in reality. The habitual tendency for discriminative thought to act as a barrier to direct experience is diminished, and the sensory world swims in close.

\section{Altering Awareness}

The experience of this shift away from daily thought patterns is described by both Lendra (speaking of The Motions) and Guardia (speaking of The Movements):

Lendra:

\footnotetext{
15 See Richards 1995, pp. 52 - 55, and Grotowski 1997b, pp. 297 - 298.
} 
I become highly aware of my body; it absorbs what I see and hear. The surroundings become one with my body, and I feel as if my body is hollow and is being lifted. (1997, p. 127)

Guardia:

It was a completely altered state of consciousness. You entered another time and space... it was like a long, long meditation... You were absorbed by the action - and that state of focus, for me, is a kind of mindfulness. Just being there, doing that, opened a very acute perception of the environment... It was a kind of communion with the forest. (2017b)

In both accounts, the heightening of sensory experience is associated with an enhanced relationship to the surrounding environment. In River Action, precisely such a state of altered consciousness was intended as a means by which to draw closer to our jungle environment, to immerse ourselves deeply in the present moment experience. Communion with the forest was precisely our intention; not only because the text we were planning to share with audiences was an ecological meditation, but - more importantly here because learning to access such a state of meditative immersion would enable us to guide audiences into a similar state.

Middleton's personal experience of working within River Action sheds some light on the nature of the meditation at the heart of the practice, 
The slight backbend in the second position brings me up against my habitual patterns of tightening the muscles around my thoracic spine. I am continually working with the mind's natural tendency to be drawn to the site of discomfort. Compulsively, I find myself 'grabbing' to the counting of my breath as a strategy for sustaining myself in the practice. But any such strategy dominates my attention. (DM)

Whilst many meditation practices, particularly in their beginning stages, involve counting or watching the breath as an exercise in concentration, the meditational task in River Action is to let the mind rest in open awareness, receptive to the whole sensory field. This is closer to a later stage of meditation practice; Varela, Thompson and Rosch write,

Eventually meditators report periods of a more panoramic perspective... Experience of panoramic awareness and of space are natural outgrowths of mindfulness/awareness meditation...

Resting in an open, panoramic awareness of the rich sensory field of the jungle is the central meditational gesture of River Action. It is one that is both challenged (as above) and supported by the particularities of the physical positions.

We are there with a will to go into deep layers of reality. To make the entrance [through] the door, you need a key.... and the key is the action in itself. Put this [key] in the precise place. Don't put it [just] anywhere because [that way] it will not open [anything]. (NN) 
Over the years, certain movements appear [for] certain works and are efficient; not necessarily the whole sequence of the Movements, maybe just one or two are the ones that appear that are necessary for that specific action... If we were working with the earth, other asanas would have appeared. (Guardia 2017b)

From this perspective, The Movements might be seen as a kind of anthology of asana-like postures, or psychophysical 'gestures', that enable a particular mode of relationship with the surrounding environment.

\footnotetext{
${ }^{16}$ See, for example, Dana R. Carney, Amy J. C. Cuddy \& Andy J. Yap (2010) Power Posing: Brief Nonverbal Displays Affect Neuroendocrine Levels and Risk Tolerance. Psychological Science Vol. 21, Issue 10, 2010. pp. 1363 - 1368
} 
The framing action with the hands had a particular potency for our work on immersive experience; a somatic 'meaning' was conveyed by the very act of positioning oneself, as it were, on a perceptual threshold; penetrating the view, we were partly in one world and, feet grounded, partly in another.

If you go deep, I get the feeling that the movement in itself is eloquent. $(N N)$

The act of angling through the portal of the hands is a relational act, replete with the somatic meaning-resonance of entering, accessing, uniting with. If our daily experience of the world is as though seen through distancing filters of conceptualisation, the essential gesture of River Action is one of piercing through that veil.

Crucially, this work on immersion is neither a chaotic plunging into raw experiencing, nor is it a process of entering into a withdrawn introspection; rather, it is a state of aligned inner and outer wakefulness. Over time, we must learn to hold in an expansive awareness, the sensing body, the attentive and receptive mind, the whole perceptual field of the world in which we find ourselves. So that, when we come to perform our work with audiences we can be wholly present with them and attentive to their needs, at the same time that we inhabit roles, speak texts, and make our own sensitised encounter with the forests in which we perform.

The repeated practice of River Action serves as an actor-training insofar as it cultivates this state of awake and expansive awareness, and prepares the performer to re-establish that state in the context of a 
participatory performance. The outer simplicity of the form allows the participant to become deeply familiar with the attentional gestures that form its inner score, and that will later be employed in the more complex and dynamic field of awareness of the performance. It is, however, training in the sense of an 'untaming' (Grotowski in Kumiega 1987, p. 230), a deconditioning of the habitual patterns of perception and mentation that divide us from our own experience $^{17}$.

Grotowski has described such a strategy of 'untaming' as 'heavy work' (Kumiega 1987, p. 230), and it should perhaps be noted that the training described here, whilst neither so intense nor extensive as the work explored in Theatre of Sources, should not be undertaken lightly. Without experienced guidance, participants may find themselves destabilized by the very forces of 'untaming' and deconditioning that the practices are designed to engage. At the same time, Grotowski noted that the paratheatrical work required 'very delicate conditions' (Kumiega 1987, p. 223) and Thomas Richards has warned against a superficial engagement in The Motions (1995, pp. 52 - 55). Without skilful handling of instructions, and duration, and without the essential attentional strategies (see Richards 1995, p. 55), a practice such as River Action might amount to little more than a physical exercise.

\section{In Chapultepec: Monitoring}

At 7 am, on a cold, wet, still-dark Mexican morning, we wait to perform El Ensueño de los Árboles in Chapultepec Park. Audience members gather in a circle to hear the opening instructions. Adame and Clay are already waiting in

17 Richards notes the error involved in attempting to apply the open vision strategy directly in performance (1995, p. 54). 
their starting positions in the nearby forest; Núñez, Guardia and Middleton will guide the audience through what amounts to an induction: first, spoken guidelines for participation; then a symbolic and playful divesting of their mobile phones, egos, mental habits, etc. (Figure 6); finally, as we step into the forest, Núñez silently signals for closed mouths, open eyes, and open ears. The monitors' first task of modelling a contemplative engagement in the experience of a morning forest walk begins.

During the course of the performance, audiences will be guided into an ever deeper engagement with their own experience through disorientating and attention-altering actions such as moving in close proximity with others, making prolonged eye-contact with strangers, joining in a collective vocal vibration, walking with eyes closed (Figure 7). If participants are to make an intensified non-daily engagement then we must first of all provide a structure through which they can divest themselves of their habitual social and conceptual patterns.

\section{I will find myself only when I get lost (NN)}

Our intention is that they should become immersed in the forest, immersed in the performance, immersed in their own actions of engagement - with one another, with the forest, and then with a single, specially chosen tree (Figure 8). Our every interaction with them - as a group, and individually - creates the fabric of their experience. The degree to which they can access a mode of 'serious play', and allow themselves to 'go deep,' when the text invites it, depends upon the quality of our interpersonal relationship with them. The 
degree to which a pathway into contemplation is made viable for them depends upon the depth of our own contemplative presence. As Guardia says, 'You only take people into immersion through example. There are no other ways to immerse people (Guardia, 2017b).

In part, the example we set is permission-giving; in part, it is demonstrating a foundational attitude which participants are invited to adopt with regard to allowing themelves to be vulnerable in the unknown of the unfolding performance.

We must go ahead of the audience in the extent of our nakedness. $(N N)$

We also go ahead of the audience in terms of our understanding of the pathways and the obstacles to immersion. Although the audience-participants in El Ensueño did not undergo the practice of River Action, they were following a similar experiential process, albeit in a milder and more aesthetic form. Clay reported,

I could see on people's faces a kind of condensed version [of our experience], and... moments of realization or of noticing something that I had already experienced, and then [I found myself] having... empathy (Clay 2017b).

Guardia states, 
You have an organic feeling of how important it is, just the way you touch them, to give them confidence and to contain them - because you have been in that place. This kind of sensibility is born from you having been in that place, in a long practice.... a mindful practice. So actions are actions of mindfulness and opening sensibility and perception (Guardia 2017b).

'Mindfulness' denotes a mode of awareness that is usually characterised, across clinical, psychological and Buddhist contexts, as

...a kind of non-elaborative, non-judgmental, present-centred awareness in which each thought, feeling, or sensation that arises in the attentional field is acknowledged and accepted as it is. (Bishop et al in Williams \& Kabat-Zinn 2013, p.43)

This describes well the attentional strategy that underlies the contemplative experience of El Ensueño. We might, then, see the task of the monitorperformers as akin to the task of the mindfulness instructor, about which Jon Kabat-Zinn writes,

Our job is to take care of the territory of direct experience in the present moment and the learning that comes out of it. This suggests that the instructor is continually engaged in mapping the territory inwardly through intimate first-person contact and discernment, moment by moment... (Williams \& Kabat-Zinn 2013, p. 297) 


\section{Conclusion}

Grotowski's work with techniques that 'bring us back to the sources of life... to organic primary experience of life' is directly drawn upon in our training as immersive theatre performers, and in our offer to audiences.

Fundamental to our work is the intention to foreground the presence of the actor in an immersive theatre context. In particular, we target the actor's ability to multi-task attentionally from a place of contemplative absorption, and to model invitationally, for audiences, a mode of active mindfulness.

The training described here is fundamentally a training in embodied awareness, carried out via energetic form and with particular attention paid to the use of the gaze and the role of intention and environment. These multiple factors influence the degree to which immersive experience is possible, through dilating sensorial sensitivity. Like Grotowski's work in Theatre of Sources, it is a training in the capacity for immersion.

The image of the actor, as in Figure 4, poised on a threshold and peering through a portal, might be taken as emblematic of the role of the performer in an immersive theatre context, inhabiting the dual space of dilated inner and outer attention. Of course, as Jon Kabat-Zinn has pointed out, 'ultimately there is no inside and no outside, only one seamless whole, awake 
and aware' (Williams \& Kabat-Zinn 2013, p. 284). With a sufficiently panoramic awareness, the performer might move seamlessly, spontaneously, through the many relational vectors that an immersive performance entails; wholly attuned to their own experience, and wholly available to the needs of the performance and the participants. 


\section{BIBLIOGRAPHY}

Clay, C., 2017a. Training Journal (Unpublished).

Clay, C., 2017b. Interview with the author. 12 July 2017, Mexico City. [Recording in possession of author].

Grimes, R. L., 1995. Beginnings in Ritual Studies (Revised Edition). Columbia: University of South Carolina Press.

Grotowski, J., 1997a. Theatre of Sources. In: R. Schechner and L. Wolford, eds. The Grotowski Sourcebook. London and New York: Routledge. pp. 252 270.

Grotowski, J., 1997b. Tu es le fils de quelqu'un. In: R. Schechner and L. Wolford, eds. The Grotowski Sourcebook. London and New York: Routledge. pp. 252 - 270.

Guardia, H., 2017a. Personal Correspondence with Middleton. Unpublished.

Guardia. H., 2017b. Interview with the authors. 12 July 2017, Mexico City. [Recording in possession of authors].

Johnson, W., 1996. The Posture of Meditation. Boulder CO: Shambhala Publications.

Kolankiewicz, L., 1979. On the Road to Active Culture. Trans. Boleslaw Taborski. Wroclaw: Instytut Laboratorium.

Kumiega, J., 1987. The Theatre of Grotowski. London and New York: Methuen.

Lendra, I. W., 1997. Bali and Grotowski: Some parallels in the training process. In: R. Schechner and L. Wolford, eds. The Grotowski Sourcebook. London and New York: Routledge. pp. 312 - 327.

Machon, J., 2009. Immersive Theatres: Intimacy and Immediacy in Contemporary Performance. London: Palgrave Macmillan.

Middleton, D., 2001. 'At Play in the Cosmos: The Theatre and Ritual of Nicolás Núñez'. TDR, 45, 4 (T172) Winter 2001. pp. 42 - 63

Núñez, N., 1996. Anthropocosmic Theatre: Rite in the Dynamics of Theatre. Amsterdam: Harwood Academic.

Richards, T. 1995. At Work with Grotowski on Physical Actions. London and New York: Routledge. 
Schechner, R., 1997. Introduction to Part II. In: R. Schechner and L. Wolford, eds. The Grotowski Sourcebook. London and New York: Routledge. pp. 207 214.

Trungpa, C., 1994. True Perception: The Path of Dharma Art. Boston: Shambhala Publications.

Varela, F.J., Thompson, E., \& Rosch, E., 1993. The Embodied Mind. Cambridge MA: MIT Press.

Williams, J. M. G. \& Kabat-Zinn, J., 2013. MIndfulness: Diverse Perspectives on its Meaning, Origins and Applications. Oxon \& New York: Routledge.

Wolford, L., 1997. Introduction to Part III. In: R. Schechner and L. Wolford, eds. The Grotowski Sourcebook. London and New York: Routledge. pp. 283 293.

Worley, L., 2010. Mudra Space Awareness: Selected Readings. Naropa University unpublished course materials. 


\section{List of Figures}

Figure 1: Nicolás Núñez leads audience members in a contemplative forest walk in El Ensueño de los Árboles, (2017) Chapultepec, Mexico City. Photo: Vicente Espinoza Mayo.

Figure 2: The team in their starting position for River Action: [ $L$ to $R$ ] Nicolás Núñez, Caroline Clay, Deborah Middleton, Domingo Adame. Photo: Sofie Iversen.

Figure 3: Nicolás Núñez transitioning into the portal position in River Action. Photo: Sofie Iversen.

Figure 4: Caroline Clay (foreground) and Deborah Middleton in the portal position of River Action. Photo: Sofie Iversen.

Figure 5: Nicolás Núñez in the second position of River Action. Photo: Sofie Iversen.

Figure 6: Audiences are symbolically divested of their egos and mental habits by relinquishing their mobile phones for the duration of the performance. El Ensueño de los Árboles, (2017) Chapultepec, Mexico City. Photo: Vicente Espinoza Mayo.

Figure 7: Caroline Clay (R) leads the serpent of participants with closed eyes. El Ensueño de los Árboles, (2017) Chapultepec, Mexico City. Photo: Vicente Espinoza Mayo.

Figure 8: Nicolás Núñez (L) with participants during a moment of contemplative contact with the tree. El Ensueño de los Árboles, (2017) Chapultepec, Mexico City. Photo: Vicente Espinoza Mayo.

Figure 9: Nicolás Núñez and Helena Guardia modelling a contemplative encounter with the tree. El Ensueño de los Árboles, (2017) Chapultepec, Mexico City. Photo: Vicente Espinoza Mayo. 